\title{
Marine Fouling Panel Survey and Assessment of Marine Alien Invasive Species in Myanmar
}

\author{
Myint Myint Khaing ${ }^{1, *}$
}

${ }^{1}$ Remote Sensing Department, Mandalay Technological University, Patheingyi, Mandalay, Myanmar Present address: Pro-Rector (Acting), Technological University (Pakokku), Pakokku, Magwe Division, Myanmar *Corresponding author: drmmkhaing@gmail.com

KEYWORDS

Environment Fouling panels Mytilopsis

\begin{abstract}
A survey on fouling using PVC panels was carried out for a period of one year in Yangon River. Additional observations on fouling of man-made structures elsewhere in Myanmar were also made in an effort to find marine alien invasive species. The Myanmar ports at Yangon, Sittway and Myeik have a long history of overseas trading with Europe since the 17th century. In addition, though the Yangon port and jetties are located upstream some 12 miles from the mouth of Yangon River, it experiences regular tidal action with seasonal brackish water conditions. Its catchment area is only 100 miles from the mouth and hence the river and its tributaries are short and small. Moreover, there are several weirs and small dams on the tributaries, which result in reduced sediment influx at the mouth and thus less turbidity. Therefore, the physiochemical conditions at Yangon port may not pose a limitation on the distribution of nuisance species that are able to survive brackish water conditions. Elsewhere, Sittway port at the mouth of the Kispanadi River also experiences regular tidal action and is directly connected to the Bay of Bengal, conditions which are favourable for the intrusion of marine nuisance species. Myeik port is located along the open shore of the Myeik, which is located near the Myeik Archipelago. The waters around the archipelago are clear and the shelf is characterized by high biodiversity. Therefore, the environment also appears to be highly favourable for alien invasive species. However, these ports have no record of the occurrence of alien invasive species in particular the Caribbean bivalve Mytilopsis sallei.
\end{abstract}

(c) The Author(s) 2018. This article is distributed under a Creative Commons Attribution-ShareAlike 4.0 International license.

\section{INTRODUCTION}

Myanmar has a long coastline that stretches approximately $2,800 \mathrm{~km}$ in the Bay of Bengal and the Andaman Sea, and there are six sea-ports currently in use. From north to south, the ports of Sittway, Thandwe, Pathein, Yangon, Myeik and Kawthoung are ports of call for small to medium size cargo ships from neighbouring countries, such as India, China, Bangladesh, Thailand, Singapore, as well as for research vessels and marine geophysical exploration vessels. In addition, Kyaukphyu Deep Sea Port and Dawei Deep Sea Port projects are being built for multipurpose development zones and transits for trans-boundary trade and transportation, for instance, from Bay of Bengal to Yunnan and from Andaman Sea to Bangkok. Of these, Sittway, Yangon and Myeik ports have a long history of overseas trading with Europe since the 17th century, and hence were selected for study. The location of the study ports for the present research project is shown in Figure 1. This project aims to assess the presence of invasive organisms being transferred by ships, either via ballast water or via fouling, with particular reference to Mytilopsis sallei (Récluz), an alien marine dreissenid bivalve originating from the Caribbean region (see e.g., Ganapati et al. 1971; Huang and Morton 1983; Tan and Morton 2006).

\section{MATERIALS AND METHODS}

Following the objectives of the present project, the occurrence of alien invasive organism was determined by collection and examination of sessile molluscs using PVC panels, as well as site observations on sessile communities present on jetty structures above low tide, with particular emphasis on determining if the alien bivalve species M. sallei originating from the Caribbean Sea was present. Occurrences of alien invasive species were examined by deploying fouling panels at the jetties following the method of collecting sessile organisms as instructed in Figure 2.

During the site visit for ballast water sampling, observations of hull fouling were also made by using small private boats from the local area. Some naval ships and fishing vessels were examined for the hull fouling while they were being docked. A total of 15 ships were checked for hull fouling during this project period.

Ballast water samples were collected from the cargoships at the Yangon ports during ballast water discharge. The samples were taken from the outlet valves of the ballast water discharge pumps. At the same time, port-water samples were also collected from the jetties. Both the ballast water samples and port-water samples were ana- 


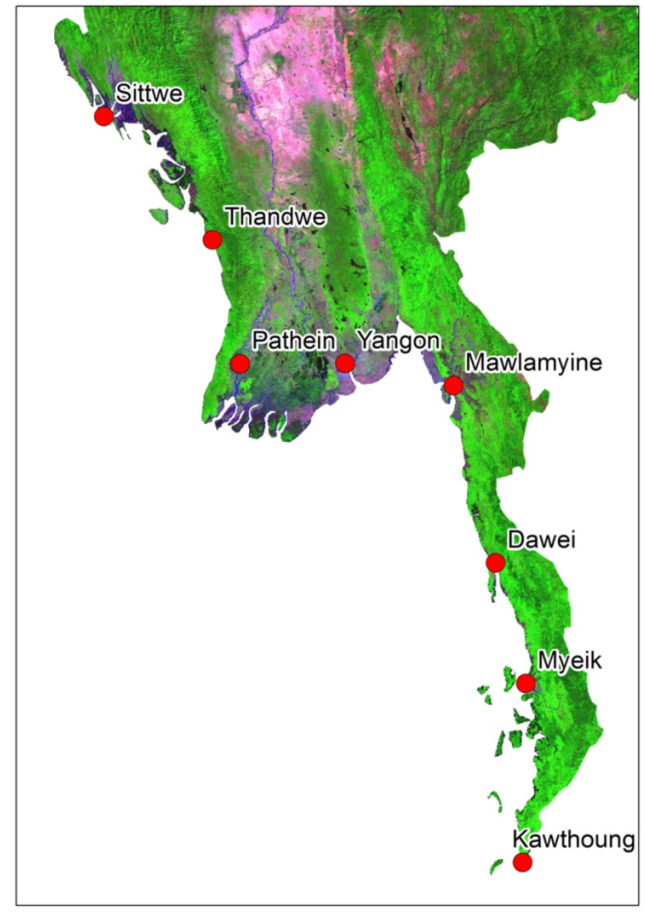

Figure 1. Locations of eight principal ports in Myanmar observed in this study.
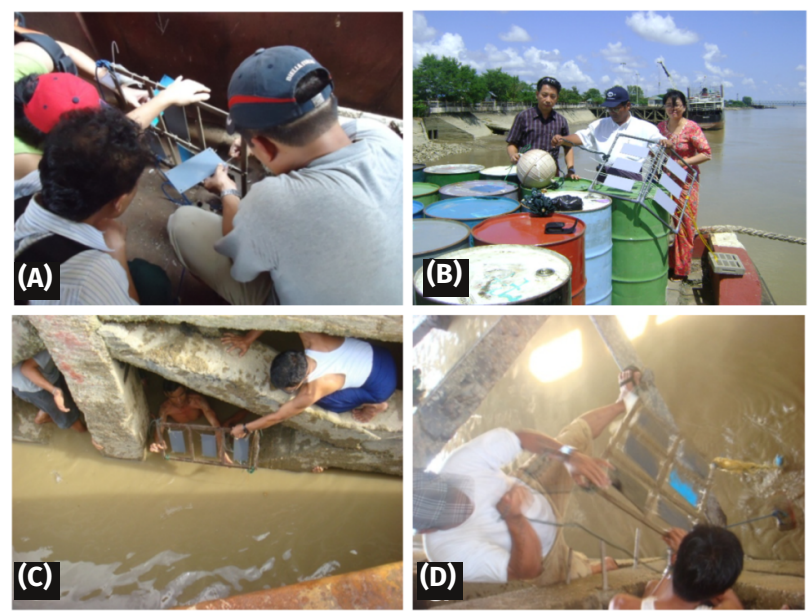

Figure 2. Deployment of fouling panels in Yangon Port, Myanmar. (A) securing panels to frame; (B) preparing to deploy fouling panels; (C) securing frame to concrete jetty; (D) recovery of panels.

lyzed for dissolved oxygen, $\mathrm{pH}$, temperature, salinity, nitrate, nitrite, phosphate and suspended solids at a commercial laboratory of MSTRD and Fishery Department of Myanmar, although these results have not been included here. A total of 30 ships were examined for ballast water analysis. Some collected water samples were sent to $\mathrm{Na}^{-}$ tional Institute of Oceanography, India, for the analyses of bacterial community profiles.

\section{RESULTS AND DISCUSSION}

3.1 Observations on fouling at Yangon port by deploying PVC panels

\subsubsection{Location of the study sites}

Among the three ports, the Yangon port is the largest port and being developed with several jetties in Myanmar.
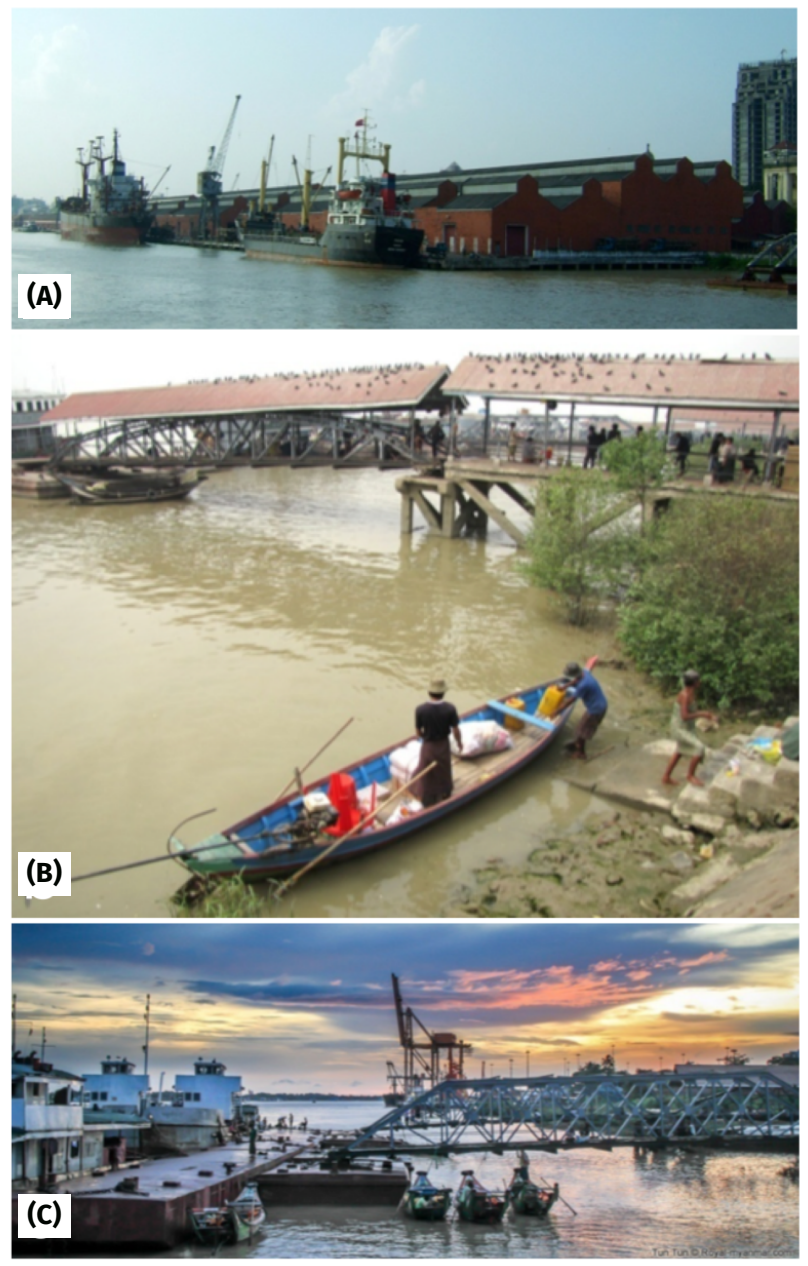

Figure 3. Yangon Port, Myanmar. (A) cargo vessels alongside godowns: (B) passenger jetty; (C) floating pontoon.

Most of the jetties are used by international vessels primarily cargo ships and container ships. Yangon port is located in the Yangon River, 12 miles upstream from the Yangon River mouth. Other jetties embarked by small vessels, such as fishery vessels, inland water transportation vessels, as well as cruise ships from Thailand and Singapore, are located further upstream from the port.

\subsubsection{Physiography of the study sites}

Yangon port experiences regular tidal action with seasonal brackish water conditions. The physicochemical conditions of the estuarine waters are influenced by the Gulf of Mottama which embraces the lower reach of the river up to 15 miles from the river mouth. The over-bank mud flats and creeks of the river are influenced by brackish water conditions during high tide, up to $5 \mathrm{~km}$ from the main river. The tide elevation in these tidal creeks is between 1 to $3 \mathrm{~m}$. The tidal flats beside the river mouth have low gradient and the inter-tidal flat is about $1.6 \mathrm{~km}$ in width. Along the estuarine lower reach of Yangon River and its short tidal creeks and channels beside the river and its tributaries, the areas are being developed into paddy fields and aquacultural farms.

\subsubsection{Site investigation}

Among the jetties of the Yangon Port, Dala jetty, Botadaung jetty, Thilawa jetty, Asia World jetty, and Nanthida jetty were visited. The concrete pillars and columns were examined to check the community of attached organisms. Locations of 


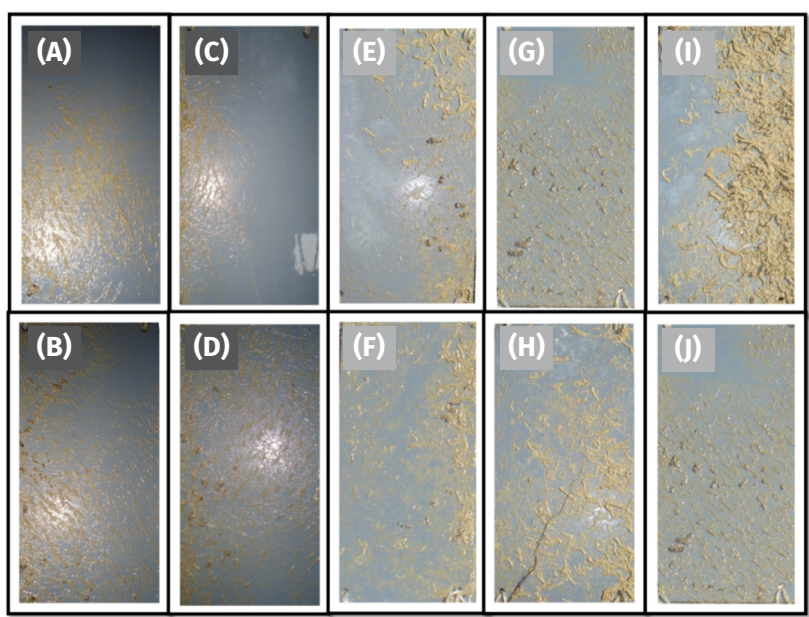

Figure 4. Surfaces (front and back) of PVC fouling panels after three months immersion over the period from July 2012 to September 2013 at a jetty in Yangon Port, Myanmar. (A, B) July to September 2012; (C, D) September to December 2012; (E, F) December 2012 to March 2013; (G, H) March to June 2013; (I, J) June to September 2013.

the jetties observed are also shown in Figure 3.

\subsubsection{Sampling}

After reconnaissance investigations, panel deployment was done at Dala jetty. Each set of observational panels comprised six PVC plates $(10 \times 10 \mathrm{~cm})$ for the observation on fouling. A weight was tied to the entire assembly to submerge it in the water. For easy recovery, the panels were deployed with nylon ropes tied to the jetty and in the visible range of the port-guards. Fouling panel survey was carried out by deploying the panels monthly, quarterly and yearly from September 2012 to September 2013.

Deployment of fouling panel in Yangon Port.

i. The subtidal fouling panels (each set comprising 3 nos of $10 \mathrm{~cm} \times 10 \mathrm{~cm}$ panels strung on rope serially and weighted down from edge of the jetty at Yangon port) were deployed monthly from September 2012 to September 2013.

ii. The 3-month panels $(3$ nos of $10 \mathrm{~cm} \times 10 \mathrm{~cm}$ panels strung on rope serially and similarly weighted down at the same location) from September 2012 to September 2013. Observations on monthly, quarterly and yearly panels were carried out every month.

iii. Each set of 3 panels were retrieved after one month, photographed (both sides) and preserved in 10\% seawater formalin, and another set of 3 panels were put into the water at the same time. Therefore, at any given time a total of 9 panels were being deployed for observation on fouling at the port (3 panels per monthly, 3 panels for quarterly and 3 panels for yearly observations).

\subsubsection{Outcome}

M. sallei was absent in all communities observed so far. In addition, there were no sessile molluscs on the PVC panels. Only tubeworms and silt were found on the fouling panels throughout the year. The panels recovered after three months is shown in Figure 4.

\subsubsection{Interpretation}

The absence of the M. sallei on collector panels and other jetty's concrete structures indicated that the species may

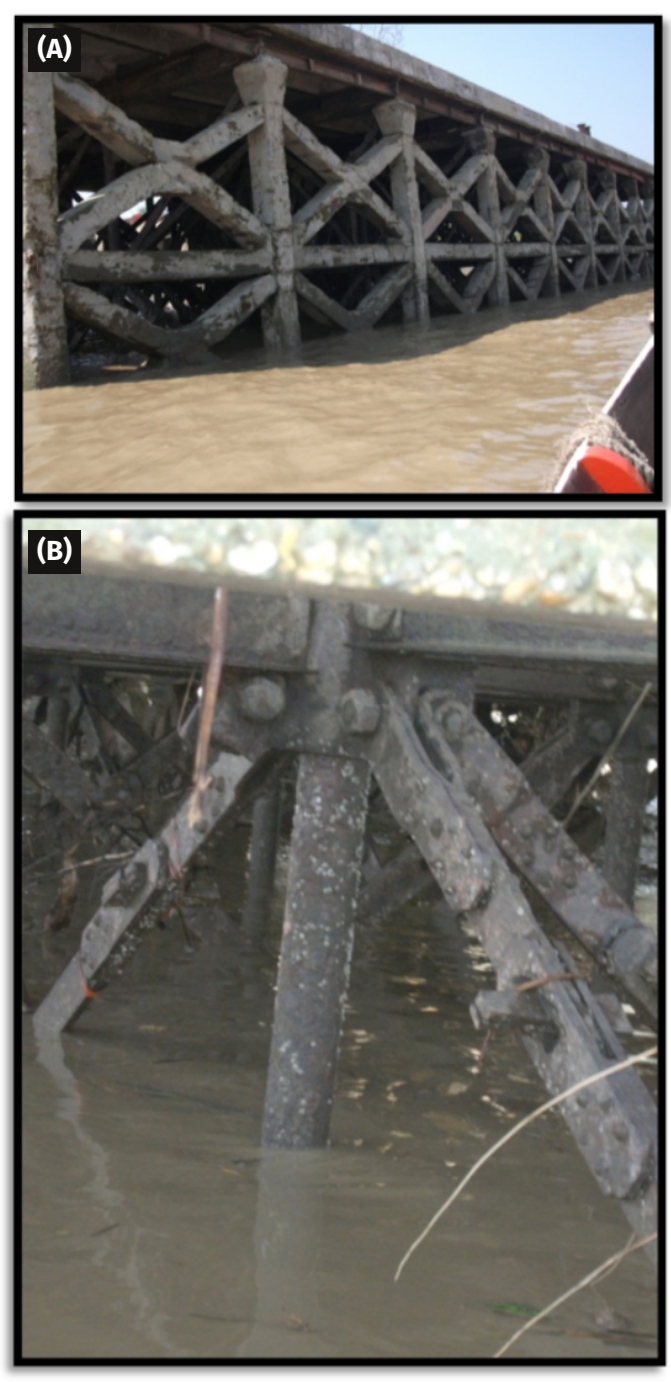

Figure 5. Structures exposed during low tide was examined for alien species at Yangon Port. (A) concrete pilings; (B) metal and wood supports.

be sparse or totally absent or conditions may not be favourable for the attachment of organisms on the panels during the study period (Figure 5). Therefore, following deduction can be remarked.

The upper reach of the Yangon River and its three major tributaries, Hlaing river, Pazundaung river and Bago river now pass through major urban areas. Largescale surface drainage and sewage systems containing a large component of anthropogenic contaminants join the river system. Several developing industrial zones are also located along the banks of the rivers.

The catchment areas of the rivers embrace the southern part of the Bago mountain ranges that are covered by rainforests, which are being deforested. Its catchment areas are only 100 miles from the mouth and hence the rivers and its tributaries are short and small. Moreover, there are several weirs and small dams on the tributaries, which result in reduced sandy or coarser sediment influx with highly muddy water in the lower reach of the river with moderately high turbidity.

Consequently, the water provided from the nearby mountain ranges to the ports is muddy. In addition, due to the embracing tidal action from the Gulf of Mottama, the waters around the ports is turbulent and becomes muddy due to the stirring up of sediments. Therefore, active estuarine conditions and bottom turbulence may result in unstable habitats for bottom-dwelling organisms. 

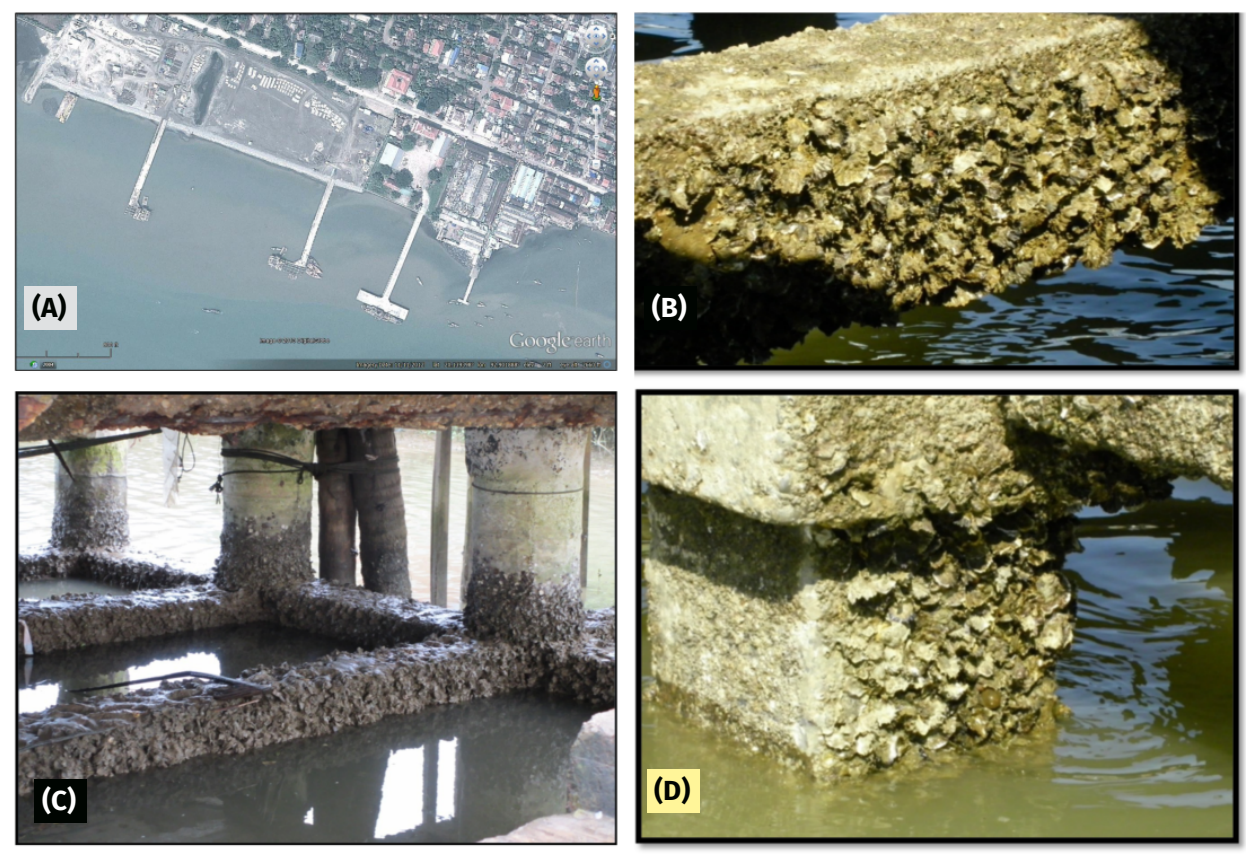

Figure 6. Sittway Port, Myanmar. (A) aerial view of jetties (image from Google Earth); (B-D) concrete structures of jetties examined for sessile molluscs (mainly oysters). The alien invasive bivalve Mytilopsis sallei was not observed at Sittway Port.

In addition, non-point source nutrient contamination from the paddy fields and farms also feed the organisms of the Yangon river estuarine system. However, the organic and inorganic contaminants from the developing industrial zones also affect the organisms. Such physicochemical conditions may not be detrimental to benthic organisms living on the riverbed.

The port waters were found to be low in dissolved oxygen, nutrients and salinity (0-7 psu). The waters contained dense muddy sediment particles rather than food particles (more than 100 to thousand ppm) and higher turbidity and larger sediment influx in port water sampling during the study period.

While carrying out ballast water analyses, it was noted that most of the shipping vessels are from ASEAN countries, as well as India and China. The quality of the water is apparently in the range of industrial discharged water with less toxic elements. In addition, due to the poorly developed chemical and petro-chemical industries, most of the goods exported are in the form of food grains and wood. Therefore, the discharged ballast water during loading raw food bases and wood to the vessels are free of harmful chemicals. In addition, most of the importing cargos are construction materials and machineries, and hence, port water to be recharged to the ballast water tank of the vessel are also free of harmful elements and chemicals due to the lack of chemical industry, petro-chemical industry and food processing industry around the jetties.

\subsubsection{Discussion}

At least two reasons were deducted; that the ecological condition is unfavourable for the sessile organism and their larvae of normal marine types. However, it is unlikely to the M. sallei which has wide tolerance to ecological factors. Therefore, the physiochemical conditions at Yangon port may not pose a limitation on the distribution of these nuisance species having wide tolerance. Another reason would be that the port handles considerably less number of vessels when compared to the neighbouring countries.

\subsection{Site observations at Sittway Port}

\subsubsection{Location}

Sittway port is located at the mouth of the Kispanadi River. There are about three jetties beside the town and mostly used by small to medium trade vessels from India and Bangladesh, exploration and supply vessels for offshore gas exploration and construction of industrial zones, fishing vessels, and other vessels used for coastal domestic trade, coastal transportation and inland water transports. The jetties are about a mile upstream from the Kispanadi river mouth. The location of the jetties at the Sittway Port is shown in Figure 6A.

\subsubsection{Physiography}

Sittway port experiences regular tide action with seasonal river in-flow conditions. The physicochemical condition of the estuarine waters is influenced by the northeastern Bay of Bengal that embrace the river up to 8 miles from the coastline and about a mile wide during high tide. Along the estuarine lower reach of the Kispanadi River and its short tidal creeks and channels, the tidal range is between 1 to 3 $\mathrm{m}$. The river and some of its small tributaries are lined with levees and most of the flood plains are being developed into paddy fields and aquaculture farms.

The middle reach of the Kispanadi River and its major tributaries flow through major vegetation and aquaculture farm areas. Its catchment area is more than 200 miles from the mouth and hence the rivers and its tributaries are long and coarse. However, there are not enough weirs and dams on the river and tributaries to disturb the transportation of sediments from the high mountain region, which result in large sediment influx at the mouth and thus high turbidity. The catchment areas of the rivers embrace the southern part of the Chin Hills mountain ranges covered by rainforests which are more than $1000 \mathrm{~m}$ in elevation.

\subsubsection{Site investigation and sampling}

Apart from the three jetties of Sittway Port, the Naval Base was visited. The concrete and iron pillars and 
columns were observed to check the community of attached organisms. Communities of fouling organisms attached on the hulls of Naval ships were also examined for M. sallei.

\subsubsection{Outcome}

M. sallei was not observed in the communities examined on the pillars and columns of the jetty as shown in Figure $6 \mathrm{~B}-\mathrm{D}$.

\subsubsection{Discussion}

Absence of $M$. sallei in communities observed on the jetty's concrete structures indicated that the species may be scarce or totally absent. Therefore, following deduction can be noted.

At the river mouth, the influx of water flowing from the Rakhine mountain ranges is muddy. In addition, due to the embracing tidal action from the Bay of Bengal, the water around the port is turbulent and become muddy by stirring-up of the previously deposited muddy sediments.

As discussed earlier, the physiochemical conditions at Sittway Port may not pose a limitation on the distribution of these nuisance species with wide tolerance. In addition, the port waters are directly connected to the Bay of Bengal and hence provide favourable conditions for the introduction of nuisance species. It should be noted that there may be no reasons for the unfavourable ecological condition for the sessile organism and opportunistic M. sallei. Therefore, it can be concluded that the jetties are being utilised by relatively fewer numbers of marine vessels compared to the neighbouring countries.

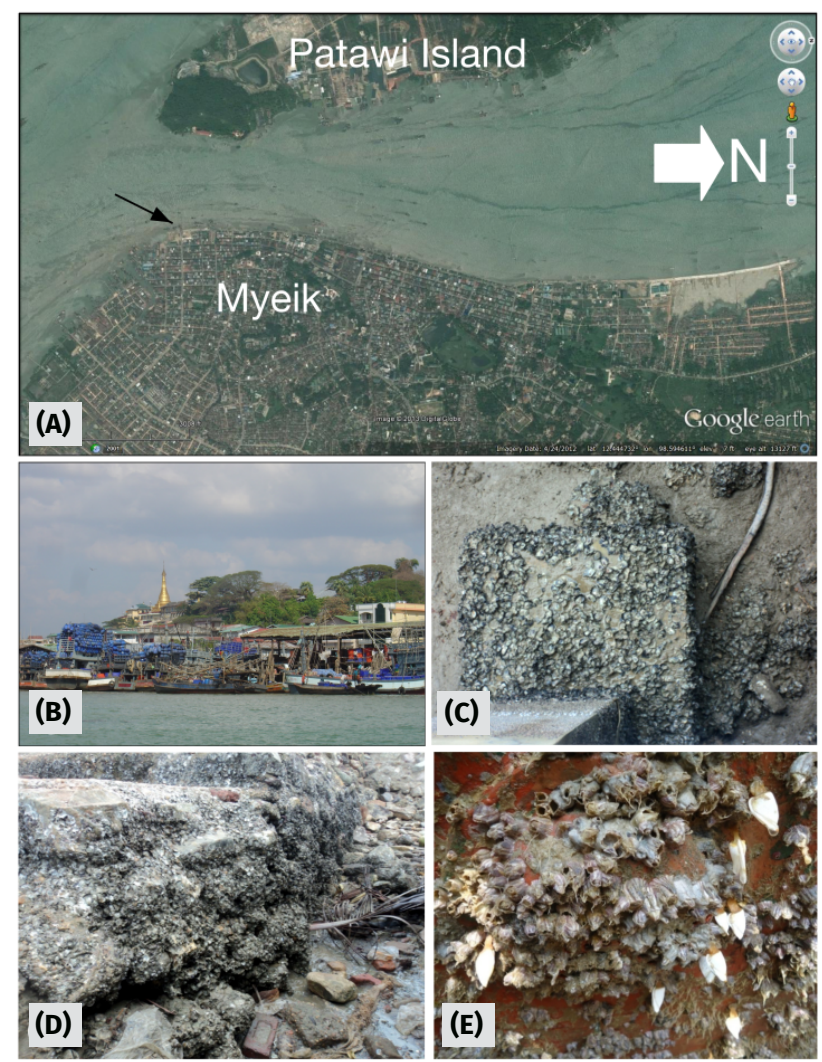

Figure 7. Myeik Port, Myanmar. (a) aerial view of port showing Naukle Jetty (black arrow) opposite Patawi Island (image from Google Earth); (b) fishing vessels off Myeik Port; (c) oysters on concrete structures; (d) fouling organisms on rocks; (e) barnacles on hull of vessel in dry dock. The alien invasive bivalve Mytilopsis sallei was not observed at Myeik Port.

\subsection{Site Observations in Myeik Port}

\subsubsection{Location of the study sites}

Myeik port is located along the open shore of the Tanintharyi coastal zone, which is east of the Myeik Archipelago. The Tanintharyi coastal zone is the longest zone of Myanmar and demarcated by the mouth of Thanlwin River in the north and Kawthaung River in the south. The length of the coastline is about $1200 \mathrm{~km}$. The zone includes Tanintharyi coastline, Myeik Archipelago and Myeik offshore shelf. The coastal plain is narrow and gradually rises towards the east to become the Tanintharyi Ranges with highest elevation of 2,073 m. The Myeik Archipelago contains about 800 islands embracing an area of approximately $34,310 \mathrm{~km}^{2}$. Coral reefs surround the outer islands and mangroves cover much of the inner islands. The densely forested hills and occasional sheltered coves provide good anchorage.

Among the three study ports, the Myeik Port is a sea-port with several jetties. Most of the jetties being utilised by fishery and trade vessels, as well as cruise ships from Thailand and Singapore. Location of the jetties along the Myeik Port is shown in Figure 7.

\subsubsection{Physiography of the study sites}

Myeik Port experiences regular tide action. The tidal range is between 1 to $2 \mathrm{~m}$. The water provided from the nearby mountain ranges to the ports is less-muddy but high particulate ratio. In addition, the water around the archipelagic islands and the port are clear and less muddy with an abundance of benthic organisms. Clear water conditions and good light penetration create favourable habitats for many reef-building marine organisms. The waters around the archipelago are clear and the shelf is characterized by high biodiversity.

\subsubsection{Site investigation and sampling}

Among the several small jetties of the Myeik Ports, the Naval Base and old jetties were visited. The communities of attached organisms on concrete and iron pillars, columns and retaining-walls were observed, as well as those on the hulls of naval ships and near-shore fishery boats.

\subsubsection{Outcomes}

The alien bivalve M. sallei was not found in the communities examined as shown in Figure 7C-E.

\subsubsection{Discussion}

Absence of the M. sallei in the communities examined on the jetty's concrete structures indicated that the species may be rare or absent. Therefore, following factors can be deduced.

In the waters of the port, the water influx flowing from the Tanintheryi mountain ranges is less muddy with high particulate ratio. In addition, due to the embracing tidal action from the Andaman Sea, the water around the port is turbulent but less muddy because of the arenaceous substrata. Estuarine conditions and bottom turbulence with sandy substrata may provide favourable habitats for bottom-dwelling organisms.

The physicochemical conditions at Myeik Port may not pose a limitation on the distribution of these nuisance species with wide tolerance. In addition, the port 
water is directly connected to the Andaman Sea and hence provides favourable conditions for the introduction of nuisance species. It should be noted that there may be no reason for the unfavourable ecological condition for the sessile organism and opportunistic M. sallei. Therefore, it is suggested that the jetties are used by fewer marine vessels relatively with the neighbouring countries which have reported the occurrence of M. sallei in their port waters, e.g., Visakhapatnam (India), Singapore, Hong Kong and Tokyo (Japan).

\section{CONCLUSIONS}

In total, three major ports, namely Yangon, Myeik, Sittway, were surveyed for baseline information and whether marine invasive species are present or not. However, fouling panel survey was carried out by monthly, quarterly and yearly only in Yangon port area from September 2012 to September 2013.

It was found that there were neither invasive bivalve species, nor any other bivalve species on the panels at Yangon port area during the one-year observation period. Mostly, tubeworms and silt were found on the fouling panels throughout the year, no other sessile organisms on the panels at all. The waters in Yangon port were characterized by:

- Higher turbidity and larger sediment influx;

- Dense muddy sediment particles (more than 100 to thousand ppm);

- $\quad$ Low salinity (0 ppm to $7 \mathrm{ppm})$

- Low dissolved oxygen and nutrients.

Acorn barnacles were found in each and every port of Myanmar visited but they were very rare in Yangon port area. The main fouling plant organism was the red macroalga Catenella sp. which occurred together with the oyster Saccostrea cucullata. The predominant oyster drill was Thais sp.

Though most nuisance species have wide ecological tolerance for varied environmental conditions, the occurrence of invasive organisms in Myanmar coastal zone have not been observed yet, in particular the Caribbean bivalve
M. sallei. Besides, as discussed earlier, the physicochemical conditions at all Ports may not pose a limitation on the distribution of these nuisance species having wide tolerance. In addition, the port water is directly connected to the open sea and hence provides favourable conditions for the introduction of nuisance species.

It is concluded that the absence of opportunistic and cosmopolitan organisms in Myanmar coastal waters appears not to be restricted by environmental factors, but more possibly due to the following factors:

i. Low intensity of the transoceanic shipping in Myanmar's seaports

ii. Less amount of ballast water discharge

iii. No alien invasive species from ballast water.

\section{ACKNOWLEDGEMENTS}

This research work was supported by ASEAN-India Cooperation Project fund through the ASEAN Subcommittee of Marine Science and Technology. The author wishes to thank Dr. A C Anil, Chief Scientist, CSIR-National Institute of Oceanography (CSIR-NIO), Dr. Tan Koh Siang, Research Fellow of National University of Singapore (NUS), and Mr. Dimas Adekhrisna, ASEAN Secretariat. The support provided by the Ministry of Transport, Myanmar and Remote Sensing Department of Mandalay Technological University is also gratefully acknowledged.

\section{REFERENCES}

Ganapati PN, Lakshmana Rao MV, Varghese AG. 1971. On Congeria sallei Récluz, a fouling bivalve mollusc in the Visakhapatnam harbour. Current Science 40: 409.

Huang ZG, Morton B. 1983. Mytilopsis sallei (Bivalvia: Dreissenoidea) established in Victoria Harbour, Hong Kong. Malacological Review 16:99-100.

Tan KS, Morton B. 2006. The invasive Caribbean bivalve Mytilopsis sallei (Dreissenidae) introduced to Singapore and Johor Bahru, Malaysia. Raffles Bulletin of Zoology 54:429-434. 